\title{
Clinical Management and Gene Mutation Analysis of Children with Congenital Hyperinsulinism in South China
}

Running Head: Clinical Management of Congenital Hyperinsulinism

Xu A ${ }^{1}$, Jing Cheng ${ }^{1}$, Huiying Sheng ${ }^{1}$, Zhe Wen², Yunting Lin ${ }^{1}$, Zhihong Zhou ${ }^{1}$, Chunhua Zeng ${ }^{1}$, Yongxian Shao ${ }^{1}, \mathrm{Cuiling} \mathrm{Li}^{1}, \mathrm{Li} \mathrm{Liu}^{1}$ *, and Xiuzhen Li ${ }^{1 *}$

${ }^{1}$ Guangzhou Women and Children's Medical Center, Department of Genetics and Endocrinology, Guangzhou, China

${ }^{2}$ Guangzhou Women and Children's Medical Center, Department of Pediatric Surgery, Guangzhou, China

\section{What is already known on this topic?}

Congenital hyperinsulinism (CHI) is a rare inherited disease characterized by unregulated insulin secretion and profound hypoglycemia. There are few reports pertaining to patients with CHI in south China.

\section{What this study adds?}

This is the first study investigating the clinical features, molecular characteristics, and treatments of $\mathrm{CHI}$ in south China and to explore the appropriate therapeutic approaches in these patients.

\section{Abstract}

Objective: To explore the clinical presentation and molecular genetics characteristics of a group of CHI patients in southern China and explore the appropriate therapeutic approaches.

Methods: We retrospectively reviewed a cohort of 65 children with CHI. Mutational analysis was carried out for KCNJ11 and ABCC8 genes. The GLUD1 gene was sequenced in patients with hyperammonaemia. GCK gene sequencing was performed in those patients with no mutation identified in the ABCC8, KCNJ11 or GLUD1 genes.

Results: ABCC8 mutations were identified in 16 children (25\% of the cohort), GLUD1 mutations were identified in 5 children, and no KCNJ11 or GCK genetic mutations were identified. Moreover, we found some unique features of $A B C C 8$ gene mutations in southern Chinese CHI patients with more novel and common mutations.The deletion/insertion mutation c.3224-3226delACC ins CAGCCAGGAACTG was found in five unrelated patients, which possibly represents a relatively common mutation in southern China. Five compound heterozygous mutations of $A B C C 8$ gene were identified in this study, and three of them were diazoxide-responsive. Forty patients were diazoxide-responsive, 13 patients were diazoxide-unresponsive and 12 patients received dietary treatment only. A pancreatectomy was performed in 10 patients who were unresponsive to medical treatment. 
Conclusion: To the best of our knowledge, this is the first study of CHI in south China. Mutations in ABCC8 are the most common causes of CHI in this cohort. Diazoxide and dietary treatment were effective in most patients. Multicentre studies are necessary to obtain the long-term follow-up characteristics of such patients at the national level.

Keywords: Congenital hyperinsulinism, Clinical management, Gene mutation

*Address for Correspondence: Xiuzhen Li MD,

Guangzhou Women and Children's Medical Center, Department of Genetics and Endocrinology, Guangzhou, 13725100840@163.com ORCID ID: orcid.org/0000-0001-5124-3051

Li Liu MD,

Guangzhou Women and Children's Medical Center, Department of Genetics and Endocrinology, Guangzhou, China

ID: orcid.org/0000-0002-6719-9830

$\mathrm{Xu} \mathrm{A}$ and Jing Cheng contributed equally to this work.

Conflict of interest: None declared

Submitted: 05-Apr-2019

Accept (10-Jun-2019)

\section{Background}

Congenital hyperinsulinism (CHI) is the most frequent cause of persistent hypoglycaemia in neonates and infants. CHI occurs due to the dysregulated and inappropriate secretion of insulin from pancreatic $\beta$ cells in relation to blood glucose levels (1). The incidence of CHI is estimated to be 1 in 40,000-50,000 live births in northern Europe (2,3) and 1 in 2,500 births in Saudi Arabia (4). However, there are no nationwide data regarding the incidence of this disorder in China, and the exact percentage of CHI cases is unknown.

Inappropriate insulin secretion can suppress the production of ketone bodies, which serve as an alternative fuels during hypoglycemia. The lack of glucose and the deprivation alternative fuels for the brain will increase the risk of brain damage in these patients (5). To date, mutations in 14 different genes (ABCC8, KCNJ11, GLUD1, GCK, HADH, SLC16A1, UCP2, HNF1A (6), HNF4A (7), HK1 (8), PGM1 (9), PMM2 (10), CACNA1D(11), and FOXA2 (12)) that lead to dysregulated secretion of insulin had been described. The most common forms of CHI are due to defects in the genes ABCC8 and KCNJ11, which encode the ATP-sensitive potassium (KATP) channel subunits of the sulfonylurea receptor (SUR1) protein and inwardly rectifying potassium channel (Kir 6.2 ) proteins, respectively (13). Both these genes are localized on chromosome 11p15.1 (14).

The clinical presentation can be varied, ranging from completely asymptomatic to mild or severe disease that is unresponsive to medication and requires surgical intervention (15). Diazoxide is the first-line agent for the treatment of CHI; it binds to the SUR1 subunits and opens the KATP channel thereby prevents depolarization of the $\beta$-cell membrane and insulin secretion (16). 
If necessary, those who are unresponsive to the medical therapy should resort to surgical treatment. Histologically, CHI is divided into three subgroups: diffuse, focal and atypical forms. Children with diffuse CHI may require a near-total pancreatectomy (with the risk of diabetes mellitus and pancreatic exocrine insufficiency) whereas the focal form will only require a limited focal lesionectomy. Conventional radiological imaging is often used but is unable to distinguish between the two forms (17). 18F-DOPA PET/CT scanning is an accurate and non-invasive technique to differentiate focal and diffuse types of CHI (18); unfortunately, this method is not available in southern mainland China. The genetic analysis would be an important tool for CHI study. Children with diffuse form of CHI due to recessive mutations in ABCC8 and KCNJ11 usually do not respond to diazoxide. Focal forms are sporadic in inheritance and associated with a paternally inherited mutation in $A B C C 8 / K C N J 11$ genes (19).

Although the clinical characteristics and genetic aetiology of CHI patients have been described in some studies in China (20,21,22), little is known about CHI in southern China. We first reported our experiences with the management of $\mathrm{CHI}$ in 12 children in 2009 (23). Furthermore, the objectives of this study were to understand the clinical presentation and molecular genetic characteristics of a group of patients with $\mathrm{CHI}$ in southern China and to explore the appropriate therapeutic approaches

\section{Subjects and Methods}

Subjects

Enrolled patients included those diagnosed with CHI who were hospitalized in the Guangzhou Women and Children's Medical Center from November 2012 to June 2017. Most of the patient with CHI came from southern China including Guangdong Province, Guangxi Province, Jiangxi Province, Hunan Province, Hubei Province, Yunnan Province and Hainan Province. Serum ammonia levels were checked in all cases. All infants and children were diagnosed with CHI based on clinical and biochemical criteria. The diagnosis of CHI was based on the following criteria, that is, whether serum insulin was simultaneously detectable ( $>2 \mathrm{mU} / \mathrm{l}$ ) with hypoglycaemia (blood glucose $<2.6 \mathrm{mmol} / \mathrm{l}$ ), along with evidence of elevated glucose requirements (glucose infusion $>8 \mathrm{mg} / \mathrm{kg} \cdot \mathrm{min}$ ), in the absence of ketosis or ketonuria, and an inappropriate glycaemic response to glucagon injection at the time of hypoglycaemia (15). Patients with a secondary cause of hyperinsulinism hypoglycaemia such as perinatal asphyxia, prematurity, intrauterine growth restriction, maternal diabetes, and syndromic forms were excluded. Children were defined as being responsive to diazoxide by maintaining blood glucose above $3.5 \mathrm{mmol} / 1$ after a short period of fasting (6) (4 h in neonates, $8 \mathrm{~h}$ in infants and $12 \mathrm{~h}$ in children). Clinical data details were obtained from medical records. The study was reviewed and approved by the Ethical Committee of Guangzhou Women and Children's Medical Center (2016022210). Genetic analysis

Genomic DNA was extracted from peripheral blood leucocytes using a kit according to the manufacturer's instructions (Qiagen, Germany). All exons and intron-exon boundaries of the ABCC8 and KCNJ11 genes were PCR amplified, purified and sequenced. The sequences were analysed and compared to the wild-type published reference sequences (NM_000525 for KCNJ11 and NM_000352.3 for ABCC8) using Chromas software (Technelysium Pty Ltd, South Brisbane, Australia). The GLUD1 gene was sequenced in patients with hyperammonaemia, whereas GCK gene sequencing was subsequently performed in those patients with no mutation identified in the ABCC8, KCNJ11 or GLUD1 genes. The new mutation sites were determined by searching the Human Gene Mutation Database (HGMD) and the NCBI database. All variations were identified in this study using the Single Nucleotide Polymorphism database (dbSNP) and the 1000 Genomes Project database. Intronic variants were analysed with GenSCAN. To test the pathogenicity of novel missense mutations, Polymorphism Phenotyping (PolyPhen, http://genetics.bwh.harvard.edu/pph) and Sorting Intolerant from Tolerant (SIFT, http://blocks.fhcrc.org/sift/SIFT.html) were used.

Treatment and follow-up 
The following aspects of CHI patients were analysed: neonatal history, clinical presentation, treatment and complications. Intravenous glucose infusion to maintain blood glucose levels of $>$ $2.8 \mathrm{mmol} / \mathrm{l}$ and nutritional therapy and diazoxide treatment were initiated immediately upon diagnosis. Nutritional therapy included frequent meals enriched with complex carbohydrates and nasogastric feeding at midnight. For those younger than six months of age, a glucose polymer, maltodextrin (Malt Extract, Wakodo, Asahi Group Foods, Ltd, Japan), was utilized, and for those older than six months, supplemental uncooked corn starch was used between meals, before bedtime and for night-time feeding through a nasogastric tube. Five patients with hyperinsulinism/hyperammonaemia (HI/HA) syndrome were performed a diagnostic tests for protein-sensitive hypoglycemia. The blood glucose concentrations of all 5 patients fell after the protein load and an age-adjusted daily requirement of protein combination with fat and carbohydrate was started.

The dosage of diazoxide was started at $10 \mathrm{mg} / \mathrm{kg}$.d and did not exceed $15 \mathrm{mg} / \mathrm{kg}$.d in three divided doses. When diazoxide treatment was effective, the dosage was reduced to the effective minimum. Oral hydrochlorothiazide (1-2 mg/kg.d) was used in conjunction with diazoxide to counteract the fluid-retaining properties of diazoxide. All patients treated with diazoxide were carefully monitored for fluid and sodium retention. In three children who were not responsive to diazoxide, octreotide (5-25 $\mu \mathrm{g} / \mathrm{kg}$.d) injections were administered.

Pancreatectomy was implemented in patients not responding to medical therapy. Clinical follow-up was initiated one month after hospital discharge and continued at subsequent intervals of 3 months. Self-monitored blood glucose levels were recorded. Brain damage was evaluated at the age of diagnosis and every 3 months of follow-up by a pediatric neurologist.

\section{Statistical analysis}

The results were analysed using the SPSS 17.0 program (International Business Machines, Armonk, NY, USA) and were expressed as the mean \pm standard error of the mean (mean \pm SE) and in percentages (\%). The Student's t-test and the Wilcoxon test were used for the statistical analysis of the data. Ali $p$ values less than 0.05 were considered significant.

\section{Results}

In this study, a total of 65 patients (47 males and 18 females) with a diagnosis of $\mathrm{CHI}$ ranging from immediately following birth to seven years were included. Twenty-three patients (35.4\%) were macrosomic, and their mean birth weight was 3,690 g. Sixty-two patients were born at term. The CHI symptoms occurred during the neonatal period in 29 patients (44.6\%), during the infancy period (1-12 months) in 26 patients (40\%) and during childhood (> 12 months) in 10 patients (15.4\%).

Of the 65 patients, 13 were diazoxide-unresponsive, 40 patients were diazoxide-responsive and 12 received dietary treatment only. The clinical and biochemical characteristics of the patients in the two groups (Group1, diazoxide-unresponsive; Group2, diazoxide-responsive or dietary treatment) are presented in Table 1. The age at onset of CHI was significantly different between these two groups. The neonatal form composed $92.3 \%$ of the group 1 , but it composed only $32.7 \%$ of the group 2 . There was a higher incidence of epilepsy in the group 2 than in the group 1 $(p<0.05)$. The time between symptom manifestation and diagnosis ranged from one day to six years, and the duration was longer in the group 2 . A patient (Case 61) in group 2,6 years old, was initially misdiagnosed as having seizure disord sefore the hypoglycemia was detected.

In our study, ABCC 8 mutations were identified in 16 children ( $25 \%$ of the cohort), and no KCNJ11 mutations were identified on KATP channel gene mutation analysis. Five patients with persistent hyperammonaemia had mutations in GLUD1 (Fig.1). No variants were found in the GCK gene. Fifteen different $A B C C 8$ mutations were discovered, five mutations were compound heterozygous, none were homozygous and 11 were heterozygous (Table 2). Among these children carried compound heterozygous mutations, three children were effective to the treatment of diazoxide, one child was ineffective to the treatment, and one child regulated with diet. The most common mutation was a deletion/insertion mutation c.3224-3226delACC ins CAGCCAGGAACTG found in five unrelated patients, which possibly represents a relatively common mutation in southern China. Five novel ABCC8 mutations (p.Phe5SerfsX72, 
p.Gln273ArgfsX85, p.Leu724del, p.Asp1447Gly and IVS 25-1G>T) were identified in this study. Of the novel mutations, two were frameshift mutations, one was a deletion mutation, one was a missense mutation and one was a splice site mutation. In accordance with the guidelines from the American College of Medical Genetics and Genomics (ACMG) (24), two variants were perceived as "pathogenic" and three variants were predicted as "likely pathogenic". A novel heterozygous variant in ABCC8 gene was identified in case 22 . The patient has now been on therapy with diazoxide for more than 1 year at the dose of $5 \mathrm{mg} / \mathbf{k g} . \mathrm{d}$ and with normal growth and development. In one case (patient 59 ), two novel nutations were identified. She was macrosomic at birth. She was first found hypoglycemia on day three after birth at a local hospital, and the hypoglycemia was improvement after frequent feeding. But, her parents did not monitor her blood glucose from then on. She admitted to our hospital at 14 months old for the brief generalized shaking several times. Clinical laboratory tests revealed hypoglycemia (blood glucose: $2.5 \mathrm{mmol} / \mathrm{L}$ ) hyperinsulinism (plasma insulin level $5.9 \mu \mathrm{IU} / \mathrm{mL}$ ) when she had an episode. Fo and four hourly uncooked cornstarch $(1.6 \mathrm{~g} / \mathrm{kg})$ could maintain the blood glucose above $3.5 \mathrm{mmol} / \mathrm{L}$. During 6 months follow-up, there was no episodes of hypoglycemia. However, she has sustained hypoglycaemic brain injury with global developmental delay.

In this study, 16 parents underwent genetic test. five patients (patients 1, 5, 10, 14 and 18) had paternally inherited monoallelic mutations. Of the five patients, three were diazoxideunresponsive, and two were diazoxide-responsive. In the three diazoxide-unresponsive patients (patients 1, 5 and 10), diffuse pancreatic disease was confirmed following surgery. One patient (patient 3) had two heterozygous mutations: one missense mutation c.314A > C (p.His105Pro) in exon 3 inherited from his father and a nonsense mutation c.2800C > T (p.Gln934X) in exon 23 inherited from his mother. He was diazoxide-unresponsive, which we had already reported (25). The 18F-DOPA PET/CT scan indicated a focal lesion in the head of the pancreas whereas the histology of the resected pancreas showed atypical form. The enlargement of pancreatic $\beta$-cell nuclei distributed in the head, body, and tail of the pancreas and mainly in the head. The abnormal active endocrine cells were not restricted to a focal lesion nor throughout the entire pancrea

The GLUD1 gene was detected in patients with hypoglycaemia, hyperinsulinism and mild hyperammonaemia. Three different heterozygous mutations in the GLUD1 gene were identified in five patients. The p.Arg322His mutation was found in patients 54, 55 and 56. Patients 55 and 56 were sisters. The mutation was autosomal dominantly inherited from their father, who was an asymptomatic carrier. The p.Ser498Leu mutation was found in patient 52 and the p. Asn463Asp mutation was found in patient 53 . All mutations have been previously reported in patients with HI/HA $(26,27,28,29)$. The serum ammonia concentration of this group of patients was 85-184 $\mu$ mol/1. After a confirmation of the diagnosis of HI/HA syndrome caused by a GLUD1 genetic defect, the patients were started on a low-protein diet (1.5g/kg.d of natural protein intake). Three patients (patients 54,55 and 56$)$ were successfully managed through the manipulation of diet alone. They have had no further hypoglycaemia episodes. The other two patients were responsive to diazoxide treatment.

$61.5 \%$ (40/65) achieved long-term stable glycaemic control by diazoxide alone. Three children who were not responsive to diazoxide, octreotide was administered. Among these three patients, two patients were unresponsive to octreotide, and one patient discontinued this drug due to severe diarrhoea. Side effects of the diazoxide treatment were observed in 32 ( $80 \%$ ) patients. Gastrointestinal disturbances such as nausea, vomiting, severe gastrointestinal upset and poor appetite occurred in $69 \%$ of patients. Six patients were fed through a nasogastric tube because of severe gastrointestinal reactions, and their blood glucose levels were kept relatively stable. Different degrees of hypertrichosis occurred in $55 \%$ (22/40) of patients during the clinical follow-up. In one case (patient 43), effective diazoxide therapy had to be stopped because of thrombocytopenic purpura.

Pancreatectomy was performed in 10 patients who were unresponsive to drugs. Nine patients were treated with subtotal pancreatectomy, and one patient received pancreatectomy twice. In patient 3 , a second resection of the pancreas was required because of sustained hypoglycaemia (25). Histological examination of the resected pancreatic tissue confirmed diffuse disease in nine 
patients and atypical form in one patient. One patient (patient 7) who underwent surgery at two months of age developed diabetes mellitus at 5 years old and was treated with insulin. Case 8 developed diabetes mellitus immediately after surgery and required insulin treatment. Two cases still had mild hypoglycaemia after surgery; one (patient 4 ) was successfully managed with regular daytime and overnight feedings, and one (patient 9) was treated with diazoxide. Only one case had malabsorption symptoms.

Diazoxide treatment was stopped in 14 of these patients (35\%) between six months and four years, and no recurrence of hypoglycaenia was observed. Eight patients with subtotal resection were able to maintain normal blood glucose and $\mathrm{HbAlc}$ levels at the follow-up duration. There were 3 diazoxide-unresponsive patients: one patient died of multiorgan failure and two patients abandoned the treatment and died of severe hypoglycemia after 3 to 7 days at home.

\section{Discussion}

In this study, we reported the clinical characteristics, laboratory data and genetic features of 65 patients with CHI, which was the largest CHI cohort in southern China. Until now, there have been no nationwide data regarding this disorder in China, although several studies have summarized the clinical and genetic characteristics of CHI in northern and eastern China $(20,21,22)$.

Of the patients with $\mathrm{CHI}$ from southern China, $32 \%$ were noted to have disease-causing mutations in our study: 14 (25\%) patients were positive for $A B C C 8$ mutations, five ( $7.8 \%$ ) patients were positive for GLUD1 mutations and 44 (67\%) patients were negative for GCK, GLUD1, ABCC8 and KCNJ11 mutations in the gene analysis. No mutations were found in the KCNJ11 gene in this study. As described in previous studies, most of the mutations identified have been detected in the KATP channel. The mutation detection rates of $A B C C 8$ and $K C N J 11$ genes reported by Kapoor et al. (6) and Snider et al. (26) were 36.3\% (109/300) and 69\% (288/417), respectively. However, a similar study conducted by a large group of Turkey found that the mutation rate in the $A B C C 8 / K C N J 11$ genes was $(\mathbf{4 8 . 6 \% ) \% ~ ( 1 7 / 3 5 ) ~ ( 3 0 ) . ~ T h i s ~ p i c k - u p ~ r a t e ~}(16 / 65,25 \%)$ is lower than those in previous reports and differed from those in recent studies in China, which reported mutation rates of approximately $44 \%$ (12/27) (31) and 67.6\% (25/32) (20) in the ABCC8 and KCNJ11 genes. Accordingly, the low mutation discovery rate in our study may be due to the difference in genetic background among most of the cases from southern China. In our study, we found the deletion/insertion mutation c.3224-3226delACC ins CAGCCAGGAACTG in five patients, which may be the most common mutation of $\mathrm{CHI}$ in the southern Chinese population. These findings indicate that a geographical distribution difference exists in the mutational spectrum of the $A B C C 8$ gene in the Chinese population. This mutation causes a frameshift and introduces a premature stop codon 75 codons downstream of the mutation, leading to the loss of the functional domain NBD2 (20). Five patients carried compound heterozygous mutations in this study. It was previously demonstrated that patients harboring compound heterozygous mutations of $A B C C 8$ gene were usually associated with medically unresponsive CHI (32). However, in the present study, three patients were effective to the treatment of diazoxide, and one patient regulated with diet. Dekel et al (33) reported that some compound heterozygous mutations may cause milder hyperinsulinism which is responsive to diazoxide. Kumaran et al.(34) also reported a case of transient hyperinsulinaemic hypoglycaemia due to a compound heterozygous mutation in $A B C C 8$. The mechanisms responsible for this clinical variability may be related to background genetic factors and other unknown factors involved in regulating gene expression (35).

Five novel mutations were found in the ABCC8 gene in five patients. One patient (patient 59) was a compound heterozygote with two novel deletion mutations, P.Gln273ArgfsX85 and P.Leu724del, and only dietary treatment could achieve stable glycaemic control.

Current medical management for CHI includes diazoxide combined with chlorothiazide as the first-line therapy (36). Diazoxide binds to the SUR1 subunit of the KATP channel and reduces insulin secretion by hyperpolarisation of the pancreatic $\beta$-cell plasma membrane (15). After diagnosis, a therapeutic trial with diazoxide was performed immediately. In our cohort, 40 ( $61.5 \%)$ 
CHI patients were diazoxide-responsive. Similar to our results, Kapoor et al. (6) recently reported that $64 \%$ of their cohort responded to diazoxide treatment. In the cohort reported by Zeynep Ş1klar et al. (19), 71\% (100/141) of Turkish patients with CHI were responsive to diazoxide treatment. The recommended dosage of diazoxide is $5-15 \mathrm{mg} / \mathrm{kg}$. (37), and the effective dosage of diazoxide is believed to always be lower than $15 \mathrm{mg} / \mathrm{kg}$.d. In our study, the initial dosage of diazoxide was $10 \mathrm{mg} / \mathrm{kg}$.d, and the minimal effective dosage was sought to maintain the stability of blood glucose. If the patient was unresponsive to a dosage of $10 \mathrm{mg} / \mathrm{kg}$.d of diazoxide, further increasing the dosage did not improve the effect but rather increased the risk of serious complications. Gastrointestinal symptoms, such as vomiting, nausea and poor appetite, were common if dosages higher than $10 \mathrm{mg} / \mathrm{kg} . \mathrm{d}$ were administered. One patient receiving effective diazoxide therapy had to stop treatment due to serious gastrointestinal symptoms, and three cases required nasogastric tube feeding. To improve the effectiveness and reduce side effects, we believe that diazoxide should be used at the minimal effective dosage.

In this study, 35 of 65 patients developed mild mental retardation including 4 patients association with HI/HA syndrome. Both low blood glucose and insufficient treatment increased the risk of neurodevelopmental impairment in CHI (38). HI/HA syndrome is caused by activating mutations in the GLUD1 gene, which encodes the intramitochondrial enzyme glutamate dehydrogenase (GDH) (39). The epilepsy and developemental problems in HI/HA syndrome are thought to be a result of recurrent hypoglycaemia, chronic hyperammonaemia or decreased brain concentrations of the neurotransmitter GABA due to increased GDH activity (27). The high rate of developmental delay in this study is likely due to the late diagnosis. Given that the clinical symptoms of this disease were not specific, and their hyperinsulinism may be less severe, more infants with CHI were misdiagnosed and not recognized until they presented with hypoglycaemic seizures weeks to months later. The earlier detection of blood glucose and serum insulin levels will be helpful for diagnosis. Therefore, neonates, infants and children should be evaluated for hypoglycaemia (40). Dietary treatment is an important aspect of care for all patients with CHI. In our study, $18 \%$ of patients could achieve glycaemic stability with dietary treatment alone. Frequent feedings and specific diets include the provision of adequate carbohydrates to maintain normoglycaemia. Dietary treatment showed a good response in some cases and should be the initial treatment for all CHI patients. Glucose polymer and uncooked corn starch were added based on the patients' age to increase the carbohydrate content. Some infants may require a nasogastric tube for regular and frequent feedings. Patients with HI/HA syndrome require a protein-restricted diet. Feeding problems such as difficulty with sucking, swallowing, vomiting and food refusal occur in a significant proportion of children with $\mathrm{CHI}$, continuous feeding through nasogastric tube or gastrostomy is required (41).

A pancreatectomy was implemented in 10 diazoxide-unresponsive CHI patients, accounting for $15.4 \%$ of all CHI patients. During surgery, none of our patients were identified to have a focal lesion. A pathological examination of pancreatic tissues revealed the diffuse form of hyperinsulinism in 9 of 10 cases. The diffuse type was the most common type of CHI in our study. The findings were similar to those reported by Bellanne'-Chantelot $58.7 \%$ (64/109)) (42) and Li et al. (89.5\%) (43). In total, 40\% (4/10) of patients with CHI unresponsive to diazoxide had АBCC 8 mutations. In these four patients with the diffuse form of CHI proved by histology, three cases carried a single heterozygous $A B C C 8$ mutation, and one case carried a compound heterozygous mutation; a segregation analysis of both parents showed that the mutation was paternally inherited in three patients and biparentally inherited in one patient. CHI with a single paternally inherited heterozygous mutation in the $A B C C 8$ gene suggests focal disease (29,37). However, Chandran et al. (44) reported that heterozygous paternal mutations cause diffuse CHI. Paternal mutations causing diffuse disease may act via a different mechanism from that of recessive mutations (45).

\section{Study Limitations}

The major limitations of our research is a single-center study other than multiple centers and cross-sectional research. Multicentre studies are necessary to obtain the long-term follow-up characteristics of such patients at the national level in the future. 


\section{Conclusion}

In summary, a genetic diagnosis was made for $32 \%$ of the patients in this large cohort. Mutations in the ABCC 8 gene were the most common identifiable cause. However, we found some unique features of $A B C C 8$ gene mutations in southern Chinese CHI patients with more novel and hot-spot mutations. Diazoxide and dietary treatment were effective in most patients. In the remaining $68 \%$ of patients, the genetic cause of hypoglycaemia remains unknown, a targeted gene panel for CHI and even a whole-exome sequencing (WES) analysis would apply in these patients.

\section{Ethics}

Ethics Committee Approval: The study was approved by the ethical committee of Guangzhou Women and Children's Medical Center(approval number:2016022210).

Informed Consent: Consent form was filled out by all parents and participants.

Peer-review: Internally peer-reviewed.

\section{Authorship Contributions}

Surgical and Medical Practices: Zhe Wen, Xu A, Zhihong Zhou

Concept: Li Liu, Xiuzhen Li, Xu A,

Design: Xu A, Jing Cheng,

Data Collection or Processing: Zhihong Zhou, Chunhua Zeng,Cuiling Li,

Analysis or Interpretation: Huiying Sheng, Yunting Lin, Yongxian Shao,

Literature Search: Xu A, Jing Cheng

Writing: Xu A, Jing Cheng, Xiuzhen Li.

Financial Disclosure:This study was supported by funding from the Science and Technology Program of Guangdong Province (No. 2017A02015111) and the Medical Scientific Research Foundation of Guangdong Province (No.A2017208).

\section{References}

1. Roženková K, Güemes M, Shah P, Hussain K. The Diagnosis and Management of Hyperinsulinaemic Hypoglycaemia. J Clin Res Pediatr Endocrinol 2015 ; 7: 86-97.

2. Bruining GJ. Recent advances in hyperinsulinism and the pathogenesis of diabetes mellitus. Curr Opin Pediatr 1990;2:758-765.

3. Otonkoski T, Ammälä C, Huopio H, Cote GJ, Chapman J, Cosgrove K, Ashfield R, Huang E, Komulainen J, Ashcroft FM, Dunne MJ, Kere J, Thomas PM. A point mutation inactivating the sulfonylurea receptor causes the severe form of persistent hyperinsulinemic hypoglycemia of infancy in Finland. Diabetes 1999; 48:408-415.

4. Arnoux JB, Verkarre V, Saint-Martin C, Montravers F, Brassier A, Valayannopoulos V, Brunelle F, Fournet JC, Robert JJ, Aigrain Y, Bellanné- Chantelot C, de Lonlay P. Congenital hyperinsulinism: current trends in diagnosis and therapy. Orphanet J Rare Dis 2011; 6: 63.

5. Hussain K, Aynsley-Green A Hyperinsulinism in infancy: understanding the pathophysiology. Int J Biochem Cell Biol 2003;35:1312- 1317. 
6. Kapoor RR, Flanagan SE, Arya VB, Shield JP, Ellard S, Hussain K. Clinical and molecular characterisation of 300 patients with congenital hyperinsulinism. Eur J Endocrinol 2013;168:557-564.

7. Kapoor RR, Heslegrave A, Hussain K. Congenital hyperinsulinism due to mutations in HNF4A and HADH. Rev Endocr Metab Disord 2010;11:185-191.

8. Pinney SE, Ganapathy K, Bradfield J, Stokes D, Sasson A, Mackiewicz K, Boodhansingh K, Hughes N, Pinney SE, Ganapathy K, Bradfield J, Stokes D, Sasson A, Mackiewicz K, Boodhansingh K, Hughes N, Becker S, Givler S, Macmullen C, Monos D, Ganguly A, Hakonarson H, Stanley CA. Dominant form of congenital hyperinsulinism maps to HK1 region on 10q. Horm Res Paediatr 2013;80:18-27.

9. Tegtmeyer LC, Rust S, van Scherpenzeel M, Ng BG, Losfeld ME, Timal S, Raymond K, He P, Ichikawa M, Veltman J, Huijben K, Shin YS, Sharma V, Adamowicz M, Lammens M, Reunert J, Witten A, Schrapers E, Matthijs G, Jaeken J, Rymen D, Stojkovic T, Laforêt P, Petit F, Aumaître O, Czarnowska E, Piraud M, Podskarbi T, Stanley CA, Matalon R, Burda P, Seyyedi S, Debus V, Socha P, Sykut-Cegielska J, van Spronsen F, de Meirleir L, Vajro P, DeClue T, Ficicioglu C, Wada Y, Wevers RA, Vanderschaeghe D, Callewaert N, Fingerhut R, van Schaftingen E, Freeze HH, Morava E, Lefeber DJ, Marquardt T. Multiple phenotypes in phosphoglucomutase 1 deficiency. N Engl J Med 2014; $370: 533-542$.

10. Cabezas OR, Flanagan SE, Stanescu H, García-Martínez E, Caswell R, Lango- Allen H, Antón-Gamero M, Argente J, Bussell AM, Brandli A, Cheshire C, Crowne E, Dumitriu S, Drynda R, Hamilton-Shield JP, Hayes W, Hofherr A,Iancu D, Issler N, Jefferies C, Jones P, Johnson M, Kesselheim A, Klootwijk E, Koettgen M, Lewis W, Martos JM, Mozere M, Norman J, Patel V, Parrish A, Pérez-Cerdá C, Pozo J, Rahman SA, Sebire N, Tekman M, Turnpenny PD, Hof WV Viering DHHM, Weedon MN, Wilson P, Guay-Woodford L, Kleta R, Hussain K, Ellard S, Bockenhauer D. Polycystic Kidney Disease with Hyperinsulinemic Hypoglycemia Caused by a Promoter Mutation in Phosphomannomutase 2. J Am Soc Nephrol 2017;28:2529-2539.

11. Flanagan SE, Vairo F, Johnson MB, Caswell R, Laver TW, Lango Allen H, Hussain K, Ellard S. A CACNA1D mutation in a patient with persistent hyperinsulinaemic hypoglycaemia, heart defects, and severe hypotonia. Pediatr Diabetes. 2017;18:320-323.

12. Giri D, Vignola ML, Gualtieri A, Scagliotti V, McNamara P, Peak M, Didi M, Gaston-Massuet C, Senniappan S. Novel FOXA2 mutation causes Hyperinsulinism, Hypopituitarism with Craniofacial and Endoderm-derived organ abnormalities. Hum Mol Genet. 2017;26:4315-4326.

13. Thomas PM, Cote GJ, Wohllk N, Haddad B, Mathew PM, Rabl W, Aguilar-Bryan L, Gagel RF, Bryan J. Mutations in the sulfonylurea receptor gene in familial persistent hyperinsulinemic hypoglycemia of infancy. Science 1995;268: 426-429

14. de Lonlay P, Fournet JC, Rahier J, Gross-Morand MS, Poggi-Travert F, Foussier V, Bonnefont JP, Brusset MC, Brunelle F, Robert JJ, Nihoul-Fékété C,Saudubray JM, Junien C. Somatic deletion of the imprinted 11p15 region in sporadic persistent hyperinsulinemic hypoglycemia of infancy is specific of focal adenomatous hyperplasia and endorses partial pancreatectomy.J Clin Invest 1997; 100:802-807.

15. Aynsley-Green A, Hussain K, Hall J, Saudubray JM, Nihoul-Fékété C, De Lonlay- Debeney P, Brunelle F, Otonkoski T, Thornton P, Lindley KJ. Practical management of hyperinsulinism in infancy. Arch Dis Child Fetal Neonatal Ed 2000;82: F98- F107.

16. Senniappan S, Shanti B, James C, Hussain K. Hyperinsulinaemic hypoglycaemia: genetic mechanisms, diagnosis and management. J Inherit Metab Dis 2012 ; 35 : 589-601.

17. Berrocal T, Luque AA, Pinilla I, Lassaletta L. Pancreatic regeneration after near- total pancreatectomy in children with nesidioblastosis. Pediatr Radiol 2005;35: 1066-1070. 
18. Mohnike K, Blankenstein O, Minn H, Mohnike W, Fuchtner F, Otonkoski T. [18F]-DOPA positron emission tomography for preoperative localization in congenital hyperinsulinism. Horm Res 2008;70:65-72.

19. Şıklar Z and Berberoğlu M. Current Status of Childhood Hyperinsulinemic Hypoglycemia in Turkey. J Clin Res Pediatr Endocrinol 2016; 8:375-380.

20. Fan ZC, Ni JW, Yang L, Hu LY, Ma SM, Mei M, Sun BJ, Wang HJ, Zhou WH.Uncovering the molecular pathogenesis of congenital hyperinsulinism by panel gene sequencing in 32 Chinese patients. Mol Genet Genomic Med 2015;3:526-536.

21. Gong C, Huang S, Su C, Qi Z, Liu F, Wu D, Cao B, Gu Y, Li W, Liang X, Liu M. Congenital hyperinsulinism in Chinese patients: 5-yr treatment outcome of 95 clinical cases with genetic analysis of 55 cases. Pediatr Diabetes. 2016;17:227-234.

22. Sang Y, Xu Z, Liu M, Yan J, Wu Y, Zhu C, Ni G. Mutational analysis of ABCC8, KCNJ11, GLUD1, HNF4A and GCK genes in 30 Chinese patients with congenital hyperinsulinism. Endocr J 2014;61:901-910.

23. Wu AW, Liu L, Li XZ, Cheng J, Zhou ZH, Zhang W. Persistent hyperinsulinemic hypoglycemia of infancy: clinicai analysis of 12 cases. Zhongguo Dang Dai Er Ke Za Zhi 2009;11 (10):809-812.

24. Richards S, Aziz N, Bale S, Bick D, Das S, Gastier-Foster J, Grody WW, Hegde M, Lyon E, Spector E, Voelkerding K, Rehm HL; ACMG Laboratory Quality Assurance Committee. Standards and guidelines for the interpretation of sequence variants: a joint consensus recommendation of the American College of Medical Genetics and Genomics and the Association for Molecular Pathology. Genet Med 2015; 17(5):405-424.

25. Zhang W, Liu L, Wen Z, Cheng J, Li C, Li X, Niu H, Wang F, Sheng H, Liu H. A compound heterozygous mutation of ABCC8 gene causing adiazoxide-unresponsive congenital hyperinsulinism with an atypicalform: Not a focal lesion in the pancreas reported by ${ }^{18}$ F-DOPA-PE T/CT scan. Gene 2015;572:222-226.

26. Snider KE, Becker S, Boyajian L, Shyng SL, MacMullen C, Hughes N, Ganapathy K, Bhatti T, Stanley CA, Ganguly A. Genotype and phenotype correlations in 417 children with congenital hyperinsulinism. J Clin Endocrinol Metab 2013;98:E355-363.

27. Kapoor RR, Flanagan SE, Fulton P, Chakrapani A, Chadefaux B, Ben-Omran T, Banerjee I, Shield JP, Ellard S, Hussain K. Hyperinsulinism- hyperammonaemia syndrome: novel mutations in the GLUD1 gene and genotype-phenotype correlations, Eur I Endocrinol 2009;161:731-735.

28. Martínez R, Fernández-Ramos C, Vela A, Velayos T, Aguayo A, Urrutia I, Rica I, Castaño L; Spanish Congenital Hyperinsulinism Group. Clinical and genetic characterization of congenital hyperinsulinism in Spain. Eur J Endocrinol 2016; 174: 717-726.

29. Faletra F, Athanasakis E, Morgan A, Biarnés X, Fornasier F, Parini R, Furlan F, Boiani A, Maiorana A, Dionisi-Vici C, Giordano L, Burlina A, Ventura A, Gasparini P. Congenital hyperinsulinism: clinical and molecular analysis of a large Italian cohort. Gene 2013;521:160-165.

30. Demirbilek H, Arya VB, Ozbek MN, Akinci A, Dogan M, Demirel F, Houghton J, Kaba S, Guzel F, Baran RT, Unal S, Tekkes S, Flanagan SE, Ellard S, Hussain K. Clinical characteristics and phenotype-genotype analysis in Turkish patients with congenital hyperinsulinism; predominance of recessive KATP channel mutations. Eur J Endocrinol. 2014;170:885-892. 31. Su C, Gong C, Sanger P, Li W, Wu D, Gu Y, Cao B. Long-term follow-up and mutation analysis of 27 chinese cases of congenital hyperinsulinism. Horm Res Paediatr 2014;81: 169-176. 
32. Suchi M, MacMullen C, Thornton PS, Ganguly A, Stanley CA, Ruchelli ED. Histopathology of congenital hyperinsulinism: retrospective study with genotype correlations. Pediatr Dev Pathol. 2003;6:322-333

33. Dekel B, Lubin D, Modan-Moses D, Quint J, Glaser B, Meyerovitch J. Compound heterozygosity for the common sulfonylurea receptor mutations can cause mild diazoxide-sensitive hyperinsulinism.Clin Pediatr (Phila). 2002;41:183-186.

34. Kumaran A, Kapoor RR, Flanagan SE, Ellard S, Hussain K. Congenital hyperinsulinism due to a compound heterozygous ABCC8 mutation with spontaneous resolution at eight weeks. Horm Res Paediatr. 2010;73:287-292.

35. Arya VB, Aziz Q, Nessa A, Tinker A, Hussain K. Congenital hyperinsulinism: clinical and molecular characterisation of compound heterozygous ABCC8 mutation responsive to Diazoxidetherapy. Int J Pediatr Endocrinol. 2014;2014:24.

36. Ismail D, Kapoor RR, Smith VV, Ashworth M, Blankenstein O, Pierro A, Flanagan SE, Ellard S, Hussain K. The heterogeneity of focal forms of congenital hyperinsulinism. J Clin Endocrinol Metab 2012;97:E94-99.

37. Yorifuji T, Horikawa R, Hasegawa T, Adachi M, Soneda S, Minagawa M, Ida S, Yonekura T, Kinoshita Y, Kanamori Y, Kitagawa H, Shinkai M, Sasaki H, Nio M; (on behalf of The Japanese Society for Pediatric Endocrinology and The Japanese Society of Pediatric Surgeons). Clinical practice guidelines for congenital hyperinsulinism. Clin Pediatr Endocrinol 2017; 26:127-152.

38. Helleskov A, Melikyan M, Globa E, Shcherderkina I, Poertner F, Larsen AM, Filipsen K, Brusgaard K, Christiansen CD, Hansen LK, Christesen HT. Both Low Blood Glucose and Insufficient Treatment Confer Risk of Neurodevelopmental Impairmentin Congenital Hyperinsulinism. A Multinational Cohort Study. Front Endocrinol (Lausanne).2017;8: 156.

39. Kawajiri M, Okano Y, Kuno M, Tokuhara D, Hase Y, Inada H, Tashiro F, Miyazaki J, Yamano T. Unregulated insulin secretion by pancreatic beta cells in hyperinsulinism/hyperammonemia syndrome: role of glutamate dehydrogenase, ATP-sensitive potassium channel, and nonselective cation channel. Pediatr Res 2006; 59: 359-364. 40. De Leon DD and Stanley CA. Congenital Hypoglycemia Disorders: New Aspects of Etiology, Diagnosis, Treatment and Outcomes: Highlights of the Proceedings of the Congenital Hypoglycemia Disorders Symposium, Philadelphia April 2016. Pediatr Diabetes 2017;18: 3-9.

41. Banerjee I, Forsythe L, Skae M, Avatapalle HB, Rigby L, Bowden LE, Craigie R, Padidela R, Ehtisham S, Patel L, Cosgrove KE, Dunne MJ, Clayton PE. Feeding Problems Are Persistent in Children with Severe Congenital Hyperinsulinism. Front Endocrinol (Lausanne) 2016; 7:8.

42. Bellanné-Chantelot C, Saint-Martin C, Ribeiro MJ, Vaury C, Verkarre V, Arnoux JB, Valayannopoulos V, Gobrecht S, Sempoux C, Rahier J, Fournet JC, Jaubert F, Aigrain Y, Nihoul-Fékété C, de Lonlay P. ABCC8 and KCNJ11 molecular spectrum of 109 patients with diazoxide-unresponsive congenital hyperinsulinism. J Med Genet 2010;47: 752-759.

43. Li J, Ma Y, Lv M, Zhou J, Liu B, Dong K, Xiao X. Chen L. Persistent hyperinsulinemic hypoglycemia of infancy: a clinical and pathological study of 19 cases in a single institution. Int J Clin Exp Pathol 2015;8:14417-14424.

44. Chandran S, Peng FY, Rajadurai VS, Lu YT, Chang KT, Flanagan SE, Ellard S, Hussain K. Paternally inherited ABCC8 mutation causing diffuse congenital hyperinsulinism. Endocrinol Diabetes Metab Case Rep 2013;2013:130041.

45. Rahman SA, Nessa A, Hussain K. Molecular mechanisms of congenital hyperinsulinism. J Mol Endocrinol 2015;54:R119-129. 
Figure 1. Distribution of patients according to mutation analysis results and treatment choices for patients with CHI.

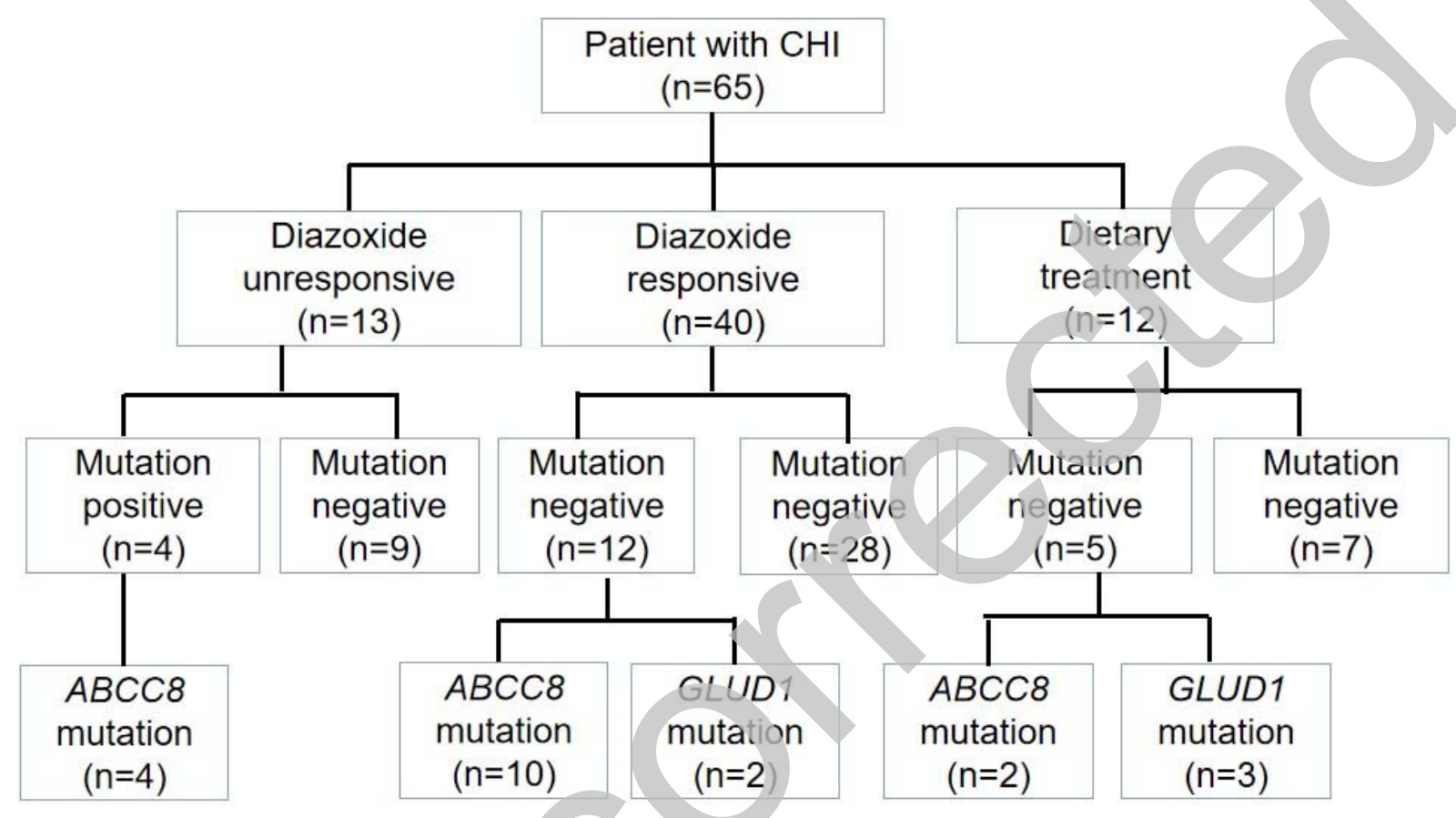




\begin{tabular}{|c|c|c|c|}
\hline & Group1 $(n=13)$ & Group2 $(\mathrm{n}=52)$ & $p$ \\
\hline Sex (Male:Female) & $9: 4$ & $36: 16$ & \\
\hline \multicolumn{4}{|l|}{ Age of onset } \\
\hline Neonate (0-4 weeks) & $\mathrm{n}=12(92.3 \%)$ & $\mathrm{n}=17(32.7 \%)$ & $<0.01$ \\
\hline Infancy (1-12 months) & $\mathrm{n}=1(7.7 \%)$ & $\mathrm{n}=25(48.1 \%)$ & $<0.01$ \\
\hline Childhood (>12 months) & 0 & $\mathrm{n}=10(19.2 \%)$ & $<0.01$ \\
\hline Birth weight (kg) & $4.0 \pm 0.6$ & $3.7 \pm 1.4$ & \\
\hline Seizures & $\mathrm{n}=4(30.8 \%)$ & $\mathrm{n}=36(69.2 \%)$ & 0.02 \\
\hline $\begin{array}{l}\text { Other (cyanosis, food refusal, } \\
\text { lethargy) }\end{array}$ & $\mathrm{n}=6(46.2 \%)$ & $\mathrm{n}=16(30.8 \%)$ & \\
\hline Time to diagnosis $\quad(\text { days })^{\mathrm{a}}$ & $35(1-120)$ & $163(1-2610)$ & \\
\hline Blood glucose (mmol/l) & $1.89 \pm 0.71$ & $1.96 \pm 0.56$ & \\
\hline Plasma insulin $(\mathrm{mmol} / \mathrm{l})^{\mathrm{a}}$ & $32.4(5.7-96.4)$ & $26.6(4.8-87.1)$ & 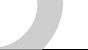 \\
\hline $\begin{array}{l}\text { Blood ammonia level } \\
(\mathrm{mmol} / \mathrm{l})\end{array}$ & $50.8 \pm 12.1$ & & \\
\hline Neurodevelopmental delay & $3(23.1 \%)$ & $32(61.5 \%)$ & 0.02 \\
\hline \multicolumn{4}{|l|}{ Mutation gene } \\
\hline АВСС8 & 5 & & \\
\hline GLUD1 & 0 & $>$ & \\
\hline
\end{tabular}

able 1. Clinical and biochemical characteristics of the $\mathrm{CHI}$ patients

Data are the mean \pm S.D. or percentage

aedian (range)

Group1:diazoxide-unresponsive

Group2: diazoxide-responsive or dietary treatmen 
Table 2. Genetic and biochemical analysis of 21 patients with mutation-positive CHI

\begin{tabular}{|c|c|c|c|c|c|c|c|c|c|c|c|c|}
\hline \multirow{3}{*}{$\begin{array}{l}\text { Patient } \\
\text { number }\end{array}$} & \multirow[t]{3}{*}{ Gender } & \multirow{3}{*}{$\begin{array}{l}\text { Gestational } \\
\text { age( week) }\end{array}$} & \multirow{3}{*}{$\begin{array}{l}\text { Birth } \\
\text { weight }(\mathrm{Kg})\end{array}$} & \multirow[t]{3}{*}{ Onset age } & \multirow{2}{*}{$\begin{array}{l}\text { Glucose levels } \\
\text { at the diagnosis }\end{array}$} & \multirow{2}{*}{$\begin{array}{l}\text { Insulin levels } \\
\text { at the diagnosis }\end{array}$} & \multicolumn{5}{|c|}{ Mutations } & \multirow[t]{3}{*}{ Treatment } \\
\hline & & & & & & & Gene & Nucleotide & Protein & Inherited from & Previously & \\
\hline & & & & & $(\mathrm{mmol} / \mathrm{L})$ & $(\mu \mathrm{IU} / \mathrm{mL})$ & & & & & reported & \\
\hline 1 & M & 38 & 3.0 & 1 day & 2.4 & & & c.3224-3226delACC ins & & 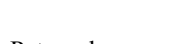 & Yes & Pancreatecto \\
\hline & & & & & & 4.8 & & AGGAACT & p. 1 hrio42Ginis $X / 5$ & Paternal & & my \\
\hline \multirow[t]{2}{*}{3} & \multirow[t]{2}{*}{ M } & \multirow[t]{2}{*}{35} & \multirow[t]{2}{*}{4.1} & \multirow[t]{2}{*}{1 day } & \multirow[t]{2}{*}{0.6} & \multirow[t]{2}{*}{38.3} & & c. $314 \mathrm{~A}>\mathrm{G}$ & p.His105 Pro & \multirow[t]{2}{*}{ Bilateral } & \multirow[t]{2}{*}{ Yes } & Pancreatecto \\
\hline & & & & & & & & c. $2800 \mathrm{C}>\mathrm{T}$ & p.Gln934X & & & my \\
\hline \multirow[t]{2}{*}{5} & \multirow[t]{2}{*}{ M } & \multirow[t]{2}{*}{39} & \multirow[t]{2}{*}{3.5} & \multirow[t]{2}{*}{3 months } & \multirow[t]{2}{*}{2.1} & & $A B C C 8$ & 3224-3226delACCinsC & \multirow{2}{*}{ p.Thr1042GlnfsX75 } & \multirow{2}{*}{ Paternal } & \multirow[t]{2}{*}{ Yes } & Pancreatecto \\
\hline & & & & & & & & AGCCAGGAACTG & & & & my \\
\hline \multirow[t]{2}{*}{10} & \multirow[t]{2}{*}{ M } & \multirow[t]{2}{*}{38} & \multirow[t]{2}{*}{4.0} & \multirow[t]{2}{*}{1 day } & \multirow{2}{*}{1.3} & \multirow{2}{*}{25.9} & \multirow[t]{2}{*}{ ABCC 8} & \multirow{2}{*}{ c. $2113 \mathrm{C}>\mathrm{T}$} & & & Yes & Pancreatecto \\
\hline & & & & & & & & & p.Arg705X & Paternal & & my \\
\hline 14 & $\mathrm{~F}$ & 39 & 2.8 & 3 days & 2.4 & 30.5 & ABCC8 & c.1879delC & p.His627MetfsX20 & Paternal & Yes & Diazoxide \\
\hline 16 & M & 38 & 4.1 & & & 26.7 & ABCC8 & c. $1990 \mathrm{C}>\mathrm{T}$ & p.Gln664X & No sample & Yes & Diazoxide \\
\hline
\end{tabular}




\begin{tabular}{|c|c|c|c|c|c|c|c|c|c|c|c|c|}
\hline 18 & M & 37 & 4.8 & 3 days & 1.6 & 16.4 & ABCC8 & $\begin{array}{l}\text { c.3224-3226delACC } \\
\text { insCAGCCAGGAACTG }\end{array}$ & p.Thr1042GlnfsX75 & Paternal & $\mathrm{Ye}$ & Diazoxide \\
\hline 21 & M & 38 & 4.8 & 3 days & 0.6 & 42.9 & $A B C C 8$ & $\begin{array}{l}\text { c.12delc } \\
\text { c.3224-3226delACC } \\
\text { insCAGCCAGGAACTG }\end{array}$ & p.Phe5SerfsX72 & No sample & Yes & Diazoxide \\
\hline 22 & M & 39 & 3.5 & 4 months & 1.8 & 8.7 & $A B C C 8$ & c. $4340 \mathrm{~A}>\mathrm{G}$ & p.Asp 1447Gly & _ & No & Diazoxide \\
\hline 23 & M & 40 & 4.35 & 3 days & 1.7 & 5.8 & АВСС 8 & $\begin{array}{l}\text { c. } 3224-3226 c \\
\text { insCAGCCA }\end{array}$ & p.Thr1042Glnis $X 75$ & - & Yes & Diazoxide \\
\hline 31 & M & 39 & 3.55 & 1 month & 2.6 & 7.3 & $A B C C 8$ & 0.7 & p.Asp1405Asn & _- & Yes & Diazoxide \\
\hline 47 & M & 34 & 3.4 & 1 day & 2.2 & 8.7 & & & p.Lle1404Thr & Maternal & Yes & Diazoxide \\
\hline 48 & F & 39 & 4.95 & 1 day & 1.7 & 13.1 & & c. $3641 \mathrm{G}>\mathrm{A}$ & $\begin{array}{l}\text { p.Arg598X } \\
\text { p.Arg1214Gln }\end{array}$ & No sample & $\begin{array}{l}\text { Yes } \\
\text { Yes }\end{array}$ & Diazoxide \\
\hline 49 & M & 38 & 4.1 & 1 day & 2.8 & 9.9 & & $\begin{array}{l}\text { c. } 1792 \mathrm{C}>\mathrm{T} \\
\text { IVS } 25-1 \mathrm{G}>\mathrm{T}\end{array}$ & p.Arg598X & No sample & $\begin{array}{l}\text { Yes } \\
\text { No }\end{array}$ & Diazoxide \\
\hline 57 & F & 41 & 3.5 & 4 days & 2.3 & 7.1 & АВСС 8 & c.12delc & p.Phe5serfsX72 & Maternal & No & Dietary \\
\hline 59 & $\mathrm{~F}$ & 40 & 4.2 & 3 days & 2.5 & & АВCC8 & $\begin{array}{l}\text { c. } 817 \mathrm{delC} \\
\text { c.2169-2171delTCT }\end{array}$ & $\begin{array}{l}\text { p.Gln273Argfsx } 85 \\
\text { p.Leu724del }\end{array}$ & No sample & $\begin{array}{l}\text { No } \\
\text { No }\end{array}$ & Dietary \\
\hline 52 & M & 38 & 3.6 & 7 months & 2.6 & 8.3 & GLUD1 & c. $1493 \mathrm{C}>\mathrm{T}$ & p.Ser498Leu & - & Yes & Diazoxide \\
\hline 53 & F & Yes & 3.8 & 13 months & 2.4 & 10.7 & GLUD1 & c. $1387 \mathrm{~A}>\mathrm{G}$ & p.Asn463Asp & _- & Yes & Diazoxide \\
\hline
\end{tabular}




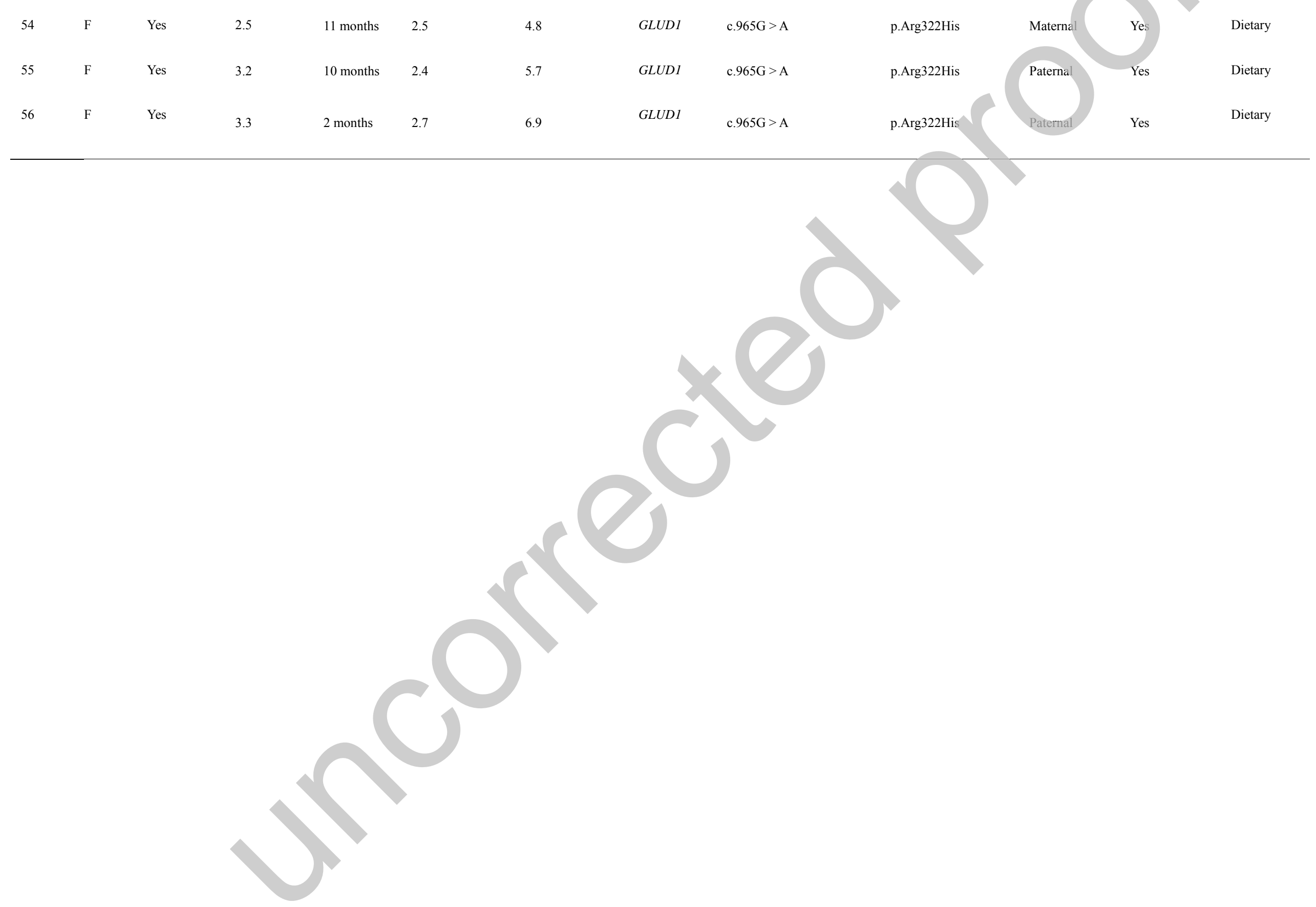

